\title{
DÜBLIN
}

Technological University Dublin ARROW@TU Dublin

2013

\section{Correspondence: Comparing LED Luminaires}

James Duff

Technological University Dublin, james.duff@arup.com

Follow this and additional works at: https://arrow.tudublin.ie/engscheleart2

Part of the Electrical and Computer Engineering Commons

\section{Recommended Citation}

Duff, J. (2013) Correspondence: Comparing LED Luminaires,Lighting Res. Technol. 2013; 45: 760-764. doi:10.1177/1477153513512459

This Article is brought to you for free and open access by the School of Electrical and Electronic Engineering at ARROW@TU Dublin. It has been accepted for inclusion in Articles by an authorized administrator of ARROW@TU Dublin. For more information, please contact arrow.admin@tudublin.ie, aisling.coyne@tudublin.ie, gerard.connolly@tudublin.ie.

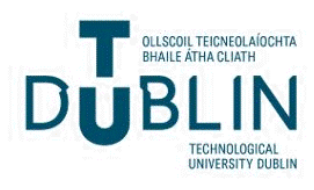




\section{Correspondence: Comparing LED Luminaires}

Dear Editor,

A recent editorial within Lighting Research and Technology ${ }^{1}$ suggests the need for 'a simple set of questions to ask the LED supplier'. This article will present such a set of questions, but also, and perhaps more importantly, a set of responses that might be considered appropriate. The information used to form these questions and answers has been drawn from a number of useful resources ${ }^{2-7}$, interaction with various lighting professionals and through the authors own experience. The purpose of these questions is to generate discussion. The author understands the questions posed can be improved upon and it is hoped that this will happen in a constructive and iterative manner.

\section{Questions for manufacturers of LED luminaires}

i. Is this LED luminaire tested in accordance with 'IESNA LM-79-08, IES Approved Method for the Electrical and Photometric Measurement of Solid-State Lighting Products'? If so, please provide a results certificate.

ii. Are the LEDs within this luminaire tested in accordance with 'IESNA LM-80-08, IES approved Method: Measuring Lumen Maintenance of Light Emitting Diode Light Sources'? If so, please provide a results certificate.

iii. Is luminaire life extrapolated in accordance with 'IESNA TM-21-11, IES Approved Method: Making Useful LED Lifetime Projections'? If it is not, is it estimated in accordance with any other standard procedure or extrapolation method?

iv. Is the data in your product specification sheet presented in accordance with 'IEC/PAS 62717 Performance requirements, LED modules for general lighting' and 'IEC/PAS 62722 Performance requirements, LED luminaires for general lighting'?

v. Who supplies the LEDs within your LED luminaires?

vi. What is the rated Luminaire Lifetime? Provide an answer in terms of hours at LxxFxx, where Lxx represents parametric failure rate and Fxx represents catastrophic failure rate.

vii. State the luminaire photometric code, as defined within IEC/PAS 62722 and IEC/PAS 62717, where the six digit code displays the important 'quality of light' parameters of an LED luminaire. It should state initial CRI, initial CCT, initial and maintained colour variation and lumen depreciation code. Please provide a lumen depreciation curve.

viii. What is the driver power factor and is the driver replaceable?

ix. What is the total luminaire Wattage, including control gear?

$\mathrm{x}$. What is the ambient temperature for which the luminaire performance is rated? Please provide information on how at least three ambient temperatures will affect the performance and rated life of the LED luminaire.

xi. What is the initial luminaire lumen output, for the specified driver current? If the luminaire is to be driven at a current that is not the standard, please provide information on how this will affect luminaire performance and life. 
xii. For what length of time is the complete luminaire warrantied for? Please supply a copy of the warranty.

\section{Acceptable Responses}

i,ii,iii. In recent years, the introduction of IESNA LM-79, IESNA LM-80 and IESNA TM-21 have afforded the opportunity for lighting designers to have LED products they are considering, tested in accordance with standardised methodologies, by an independent laboratory. Results certificates produced from these offer a wide variety of information relating to the probable performance of an LED product. All reputable manufacturers of LED luminaires and LED modules are testing to this standard and as such, the author requires that all LED products are independently tested in accordance with these standards and results certificates provided.

iv. Both IEC/PAS 62717 and IEC/PAS 62722 deal with a standardized set of quality criteria that LED modules and LED luminaires should be compared upon. This question is asked to raise awareness of both standards, in the hope that manufacturers will eventually move towards producing data sheets that contain all the information necessary to accurately compare LED luminaires. This information is not available at present.

v. Some reputable suppliers of LED chips and modules are; Cree, ASM Pacific, Philips, Osram, Epistar / Intermolecular, Nichia, Xicato, Citizen, Samsung, Bridgelux and Sharp, but this list is far from exhaustive. LED luminaire manufacturers that refuse to disclose the manufacturer of the LED chips within their luminaires should be treated with caution.

vi. Luminaire lifetime with good quality products for general lighting is typically L70F10 for 50,000 hours. This may shorten, or be stated as L70F50, for decorative or some architectural type luminaires and will vary for luminaires in different ambient temperatures.

vii. The first half (CRI and CCT) of the IEC/PAS photometric code will differ on a project specific basis, but the latter half, for good quality products, should be within a 3-step MacAdam ellipse initially and within a 3-step Macadam ellipse through lumen maintenance (for white light), combined with a lumen maintenance of code 9 or better. Again, this may shift for decorative, external and architectural applications and products of lesser quality will generally show larger colour shift and greater lumen depreciation.

viii. Care should be taken with replaceable drivers, as by law and in accordance with European Commission Electromagnetic Compatibility Directive 2004/108/EC, they cannot simply be replaced on-site using a plug and play approach. This is currently not enforced, but if an LED module or driver fails, the entire fitting should be replaced or a single component replaced, and the fitting re-tested with the new component installed. Combine this with the fragile nature of electronic components within an LED luminaire and the wide range of replacements available, and it makes sense that replaceable drivers should be avoided when possible, as they are likely to cause unforeseen compatibility issues in the future.

ix. The quoted total Wattage should be given inclusive of control gear losses.

x. Increased ambient temperatures will generally decrease efficacy and shorten rated life. Reputable manufacturers will be able to supply information about how three ambient temperatures affect all of these parameters. 
xi. Driver current affects lumen output, efficacy and luminaire life. Typically, increased drive currents will increase lumen output, but reduce efficacy and decrease life. Drive currents that are to be used on projects should be compared with drive currents used during LM-80 testing.

xii. Most reputable manufacturers of LED luminaires will provide a standard product warranty of five years. It should be noted that some of the best LED manufacturers now offer a ten year warranty, as standard, on their external LED luminaires, inclusive of all luminaire components. A copy of all product warranties should be obtained and examined, as they can often be misleading. Ensure that the warranty states very clearly what parameters will need to have drifted and how much they will need to have drifted by, before the luminaire is replaced. Also be sure that all components are coved in the event of failure, i.e. the warranty should cover driver, heat sink, LED module, housing, etc.

\section{The role of mock-ups}

Despite the quality criteria outlined, there are some aspects of LED quality which are best assessed using first-hand experience. Flicker and dimming are not discussed above. A combination of percentage flicker and flicker index can be used to estimate the stroboscopic effect of a luminaire. Dimming is frequently specified by the protocol selected, but a common complaint is that LED luminaires will not dim to $1 \%$, or even below $10 \%$, of full lumen output. Both of these issues are easily solved with a simple mock-up, but tricky to quantify through questions and answers. Aside from resolving these issues, if multiple luminaires are included in the mock-up, the designer and client can obtain personal experience of initial colour variation in the luminaire batch and compare this with colour variation between surrounding traditional source luminaires. This should leave the client and designer with few surprises when the product is finally installed on-site.

\section{References}

1. Boyce P. R. Editorial: LEDs are the answer, now what's the question? Lighting Research and Technology 2013 45: 265.

2. The Illuminating Society of North America. LM-79-08, IES Approved Method for the Electrical and Photometric Measurement of Solid-State Lighting Products. ISBN: 978-087995-226-6.

3. The Illuminating Society of North America. LM-80-08, IES Approved Method: Measuring Lumen Maintenance of Light Emitting Diode Light Sources. ISBN: 978-0-87995-227-3.

4. The Illuminating Society of North America. TM-21-11, IES Approved Method: Making Useful LED Lifetime Projections. ISBN: 978-0-87995-227-3.

5. International Electrotechnical Commission. Publically Available Standard 62722 Performance requirements - LED luminaires for general lighting. ISBN 978-2-88912-567-8.

6. International Electrotechnical Commission. Publically Available Standard 62717 Performance requirements - LED modules for general lighting. ISBN 978-2-88912-476-3

7. Implementing Directive 2004/108/EC of the European Parliament and of the Council on the approximation of the laws of the Member States relating to electromagnetic compatibility and repealing Directive. Official Journal of the European Union. Commission Regulation 89/336/EEC. 2004. 


\section{Acknowledgements}

The questions above have been extracted from a forthcoming paper in the Chartered Institute of Building Services Ireland, Sustainable Design and Research Journal, available at http://arrow.dit.ie/sdar from 05/11/2013.

James Thomas Duff

Lighting Designer, Arup

PhD Student, Dublin Institute of Technology 